\title{
Editorial: Ten years
}

Ten years. That is a long time in any business. In marketing, it ought to be considerably longer. After all, marketing is where the creative energy is supposed to lie. Marketing is from where new innovations, whether of product or message, are intended to emerge.

Do you remember where you were ten years ago? It was not all that long after the Berlin Wall had come down, and a new politic, combined with new hope for the future was sweeping across Eastern Europe - although dark clouds were already hovering over the remnants of Tito's Yugoslavia.

John Major was celebrating his unexpected return to Downing Street. Tony Blair remained a dim and distant possibility for becoming a UK Prime Minister, and George W. Bush was not even a dim and distant possibility as President of the USA.

News at Ten was still at ten o'clock.

Brookside was anticipating the wave of DIY home improvement offerings by demonstrating how to dispose of an unwanted corpse under the patio.

Although some things take longer to change: had you been so minded you could have caught Delia Smith, in 1993, regaling you with details of summer recipes. Likewise, over the water, Martha Stewart set all homestyle trends.

Ten years should be a very long time in the development of business thinking. And one would expect a journal devoted to the cutting edge of that thought to change greatly over that time.

So, as the tenth year of the Journal of Database Marketing approached - and as discussions about its future direction (of which, more later) took place - it seemed to be an appropriate point for retrospection. I spent a pleasant hour or so perusing topics that have preoccupied our readers and contributors over the years. I also revisited the first issue: to see what was current then.

The picture that emerges is not quite as optimistic as I had hoped.

I found some change, but equally, some concerns that could be as valid today as they were way back then.

In terms of papers, there was quite an interest in technology and technique. Questions were being asked about the efficacy of neural nets, CHAID and different approaches to segmentation. Lifestyle lists and databases were clearly an issue. Meanwhile, the treatment of databases seemed to be far more rudimentary than a similar piece might be today. There was, too, the same concern with legislation emerging from the EU. Again, therefore, little change there.

Much more interesting was the editorial, which one might have expected to highlight the concerns of the day. The inaugural issue's editorial was well provided by Russell Logan, and the content was, sadly, a subject that is still of concern to me; the problem of GIGO - garbage in, garbage out. The simple message in the editorial was that, unless one had decent quality data in one's database - and unless the interpretation of those data was carried out intelligently - then one was likely to be doing as much harm as good to one's relationship with one's customers.

Has that changed much? At the margins, I think some of the worst 
excesses that we as an industry used to commit have now been tightened up. (I speak here as someone who has been responsible for such errors in the past: eternal apologies to the poor woman whose address was substituted for the sample address in a mailing for a well-known make of car - and who ended up receiving 4,000 identical pieces of mail in one morning's post!)

The industry has been professionalised. The quality of training, in large part thanks to the Institute of Direct Marketing, is immeasurably better than it was ten years ago. Many companies that would never have considered database marketing are now doing so - albeit under the guise of disciplines such as customer relationship management (CRM). The type of person involved in 'database marketing' is certainly higher salaried owing, in large part, to the arrival on the scene of the big consultancies (and the parallel discovery that major amounts of money need to be spent if companies wish to participate in the CRM revolution).

So. So far, so good.

Many of today's concerns may be the same. But I think we have genuinely moved on. Ten years ago, the focus was often on the technology or the underlying maths. That is certainly one difference between now and then: the level of maths deemed necessary or acceptable to make a point has dwindled. That almost certainly reflects an industry that is maturing. Practitioners now take it for granted that they have experts behind the scenes who will make sense of the algebra for them - allowing them to get on with the business of decision making for which they are being paid.

The language has changed. You will find few individuals nowadays quite so focused on database marketing as you would have done ten years back. Instead, the talk is all of relationship marketing — or customer relationship marketing. Yet the concerns are very similar.

At one level, that reflects little more than a change in jargon, because if marketing creatives are good at one thing it is inventing new buzzwords every few years to reinvigorate interest in an old subject. Database marketing ... relationship marketing ... CRM. All these words have, at their heart, the idea that, if you understand your customers better, identify the needs of specific target groups within your overall base and then focus appropriately on those niche segments, you will do better than if you treat all your customers the same.

If it is right to behave in that way, the same issues will come back time and time again: data quality; frequency of contact; measurement; personalisation techniques; the legal framework within which you are allowed to act.

Yes. All that is the same. But two things have changed. First, as hinted at above, there are more practitioners, and more professional practitioners. Tasks that would, in the past, have been managed by some direct marketing/statistical Jack or Jill of all trades are now apportioned between a number of experts.

Specifically, the technicians are now trained better, and are allowed to get on with the technical things that they do best. Marketers need to know what a relational database is capable of: what they can do with interactive voice response; or when online 'bounceback' is appropriate. They really do not need to be over-involved in the detail of how it works.

Secondly, there has been a realisation that for CRM to work, it cannot be grafted on to an organisation courtesy of one part of the marketing department. In their wide-ranging exploration of CRM and value bases in UK industry, QCi conclude that one absolute determinant 
of success for organisations today is that there should be a recognition of customers at the highest level within the organisation - and that this should probably be reflected by board-level responsibility for CRM. No longer is it an operational skill, it has become a strategic discipline.

I began by alluding to changes afoot in the Journal. Ten years, after all, is a good time to reflect - but only if that is done with a view to learning from the past and applying it to the future.

From Volume 11 the title changes to, Journal of Database Marketing \& Customer Strategy Management, still recognising its concerns with database marketing, because that is where our roots lie, but also recognising that the world has evolved, and so too has database marketing, into CRM.

Naturally, there must be a change in emphasis. First, our focus will be more strategic, and the reasons for that have already been rehearsed above. Secondly, we will widen our scope to look at other channels of communication beyond the database. In practice, this is little more than an acknowledgment of what happens already.
Henceforth, however, we will look equally at areas such as e-business; customer services (call centres); customer management; customer retention/loyalty; key account management (KAM); multi-channel; data quality and legal compliance.

The list is not comprehensive. It cannot be. As new areas associated with the management of customers become live, so we will consider them for inclusion - discarding, too, areas that are no longer deemed relevant.

Ten years is a long time in the development of any product, and we have enjoyed ten years of success to date, by staying in touch with our readers' interests, and also by carefully listening to their comments.

We believe that, in making this change, we have listened again. We will continue to listen - and if you feel strongly enough to dissent from our thinking, then please inform us, because not only do we feel that CRM is the way for business to go in the future: we also believe in practising it ourselves.

JOHN OZIMEK Managing Editor 